\title{
A research-informed web-based professional development toolkit to support technology-enhanced mathematics teaching at scale
}

\author{
Alison Clark-Wilson ${ }^{1}$ (D) $\cdot$ Celia Hoyles $^{1}$
}

Published online: 22 August 2018

(C) The Author(s) 2018

\begin{abstract}
We report a new phase of research of the scaling of Cornerstone Maths (CM), technologyenhanced curriculum units for lower secondary mathematics that embed dynamic mathematical technology (DMT). These combine web-based DMT, pupil and teacher materials, and teacher professional development that focus on developing the mathematical knowledge and pedagogies for teaching with technology. This paper presents the background research with teachers using CM (111 teachers from 42 London secondary schools in the period 2014-2017) that suggests the need for a web-based "professional development toolkit" to support the sustainability of the innovation and "within-school" scaling beyond the timeline of the funded project. It concludes with the research basis of the toolkit's design principles and structure that are designed to support teachers to implement DMT in their classrooms.
\end{abstract}

Keywords Dynamic mathematical technology - Landmark activities · Professional development . Linear function · Professional development toolkit

\section{Introduction}

\subsection{Brief overview of Cornerstone Maths}

The Cornerstone Maths project began in England in 2011 by designing curriculum units that embed digital technology for learning mathematics, henceforth called dynamic mathematical technology (DMT). We define DMT as a subset of technology with multiple, dynamically linked, mathematical representations that can be manipulated so users can engage with

Electronic supplementary material The online version of this article (https://doi.org/10.1007/s10649-0189836-1) contains supplementary material, which is available to authorized users.

Alison Clark-Wilson

a.clark-wilson@ucl.ac.uk

1 UCL Knowledge Lab, UCL Institute of Education, University College London, 23-29 Emerald Street, London WC1N 3QS, UK 
underlying concepts and relationships. Such technologies offer the potential for teachers and pupils to (re-)express their mathematical understandings. Cornerstone Maths (CM) units (each 8-14 teaching hours) stimulate engagement with mathematics by:

- Focusing on offering dynamic links between key representations of mathematical ideas that are central to lower secondary mathematics curricular, that is algebraic patterns and expressions, linear functions, and geometric similarity

- Providing an environment for pupils to explore, make conjectures, and solve problems within guided structured activities (outlined in teacher and pupil materials)

- Embedding activities within "realistic" contexts

The CM project has evolved over several research phases since 2011. Initially, the central concern was the design and evaluation of $\mathrm{CM}$ units and establishing learning gains for a diverse sample of pupils in English schools (Hoyles, Noss, Vahey, \& Roschelle, 2013; Sturman \& Cooper, 2012). Then research identified the processes of scaling and spreading the innovation to more schools and teachers, and the factors that influenced how teachers and schools continued using the CM curriculum units after researcher support faded (Clark-Wilson, Hoyles, Noss, Vahey, \& Roschelle, 2015). This work revealed the need for a deeper articulation of the complexities underpinning mathematics teachers" "pedagogical technology knowledge" (Thomas \& Hong, 2013; Thomas \& Palmer, 2014), henceforth we refer to as MPTK $^{1}$, which we describe in Section 3.2 in more detail. As CM has scaled to hundreds of classrooms in England, the Dynamic Technology for Dynamic Mathematics (DTDM) project has started to undertake this articulation and to document and seek to explain how CM is both implemented and transformed over time through teachers' practices (ClarkWilson \& Hoyles, 2017). We see this paper as one step in responding to the call for further studies that "frame large-scale instructional improvement as an explicit focus of investigation" (Cobb, Jackson, Smith, \& Henrick, 2017, p. 1), in our case with the added complexity of introducing the use of DMT as a catalyst for improvement, which inevitably introduces both barriers and obstacles for adoption (Borneleit, Danckwerts, Henn, \& Weigand, 2001). Central to this endeavor is the goal to devise effective professional development support that allows for legitimate adaptations of the innovation that retains the essence of the innovation while peripheral aspects might change.

While shaped by the mathematical focus under study, the professional development sets out first to develop teachers' MPTK, a theoretical construct that combines Ball's "Mathematical Knowledge for Teaching" Ball, Hill, \& Bass, 2005) with the process of instrumental genesis (Guin \& Trouche, 1999) and teacher affect (Schoenfeld, 2011); and second to explore the role of "multipliers", in our case CM champions, teachers who had already engaged with CM professional development (PD), piloted CM activities in their own classrooms and led PD for colleagues in their own school (Roesken-Winter, Schüler, Stahnke, \& Blomeke, 2015, p. 14). This latter activity needed in-school support. Thus, the aim of the paper is to communicate the interplay of research and development that led to the design of a prototype web-based professional development toolkit to be used in schools by the CM champions. There is no overarching theoretical framework on which to draw for such a toolkit. Rather, we provide research background underpinning the selection of its elements.

\footnotetext{
${ }^{1}$ We add the letter "M" to Thomas and colleagues' construct of pedagogical technology knowledge (PTK) to highlight the focus on mathematics.
} 


\section{2 "Scaling-up" use of DMT in the English school setting}

The national curriculum for mathematics, which was introduced in England in 2012, specifies the content of the school mathematics curriculum (5-16 years) but offers only brief pedagogical guidance with regard to the use of technology, "teachers should use their judgement about when ICT tools should be used" and offers no exemplification to support teachers to make such judgements (Department of Education, 2013, p. 2). Consequently, there are no governmentfunded initiatives to support neither secondary school mathematics teachers to develop how they integrate DMT into their classroom practices nor for mathematics departments to embed such approaches within their school-designed schemes of work. Some use of technology across the secondary curriculum is expected and lightly monitored within the school inspection regime. Hence, we judged it important to design and test an in-school PD toolkit as that could help our multipliers in schools to both support other colleagues and to develop as future leaders.

Earlier CM research resulted in the development of a theoretical frame that conceptualized the products and processes of scaling within the English school context (Clark-Wilson et al., 2015, p. 84). By products, we mean the quantifiable measures that indicate the spread of the CM innovation, for example, by the number of schools reached. Processes are the means through which spread is achieved. These are contextually and culturally located, shaped by the prevailing mathematical culture in classrooms and schools. Within-school scaling of CM can be conceived in terms of the buy-in and the penetration within the mathematics department. Key factors for school buy-in include school-devised methods to evaluate pupils' outcomes, the development of school-based PD, and planned opportunities for teachers' collaborative work to embed CM curriculum units within the localized schemes of work. In addition, our earlier research concluded that departmental penetration of $\mathrm{CM}$ was particularly reliant on the emergence of a lead practitioner (the local multiplier in the school) and the provision of peersupport for participating teachers (Clark-Wilson et al., 2015).

The growing body of research into the scaling of curriculum innovations adopts more traditional top-down cascade models involving PD multipliers (see example, Roesken-Winter, Hoyles, \& Blömeke, 2015). Our research context differs in that we are concerned not only with reaching many schools but also with sustaining the innovation within individual schools, an area that we believe to be under-researched. Although there are online PD resources that aim to support within-school PD (e.g., Bowland Maths, 2007), some of which do address technology use in mathematics specifically (for example, EdUmatics, see Aldon et al., 2012); little is known of the impact of these PD resources on teachers' knowledge and practice and ultimately, on resulting pupil learning outcomes.

Moreover, there are contextual factors that we conjecture have a profound influence on these outcomes, schools in England are largely autonomous and in competition with each other; they are subject to a dominant inspection and accountability regime; and crucially there is a shortage of qualified mathematics teachers and widespread challenges of teacher recruitment and retention. Consequently, high numbers of mathematics teachers leave and join school mathematics departments each year. This teacher churn, which is a particular problem in London where the research took place (see Des Clayes, 2017), is an additional barrier to embedding and sustaining an innovation in school. Hence, a research-informed web-based toolkit would be best placed to support sustainability through the necessary regular cycles of school-based PD.

With this background, we adopted a design-based approach to develop a web-based professional development toolkit that could be used by existing CM schools as a vehicle for 
inducting new teachers to the $\mathrm{CM}$ teaching approaches. The limited research on sustainability within education emphasizes "durable continuation", a temporal consideration of whether the innovation is still being used months or years later after the initial funding or initiative has ended (Zehetmeier \& Krainer, 2011). Furthermore, this use is often evaluated at an individual teacher level with teachers who have been directly involved in the innovation. At the school level, research on sustainability identifies the importance of policy levers, school capacity, and the school infrastructure (Earl, Warson, \& Katz, 2003). Furthermore, Coburn's (2003) review noted additional factors: a professional community of colleagues; knowledgeable and supportive leadership; and the need to provide "schools with the tools they will need to sustain the reform, especially after initial influx of resources dissipates" (Coburn, 2003 p. 6). The CM PD toolkit was designed as just such a set of tools. Before outlining the toolkit, we present the main elements of the overarching research.

\section{Dynamic Technologies for Dynamic Mathematics: theoretical background}

\subsection{Mathematics pedagogical technology knowledge}

We adopted the framework developed by Thomas and colleagues, (mathematical) "Pedagogical Technology Knowledge" (Thomas \& Hong, 2013; Thomas \& Palmer, 2014), henceforth we call MPTK, which is shown in Fig. 1.

Briefly, these interrelated components are:

- Pedagogical knowledge: First suggested by Shulman (1987), this is a teacher's knowledge of the "broad principles and strategies of classroom management and organization that appear to transcend subject matter" (p. 8).

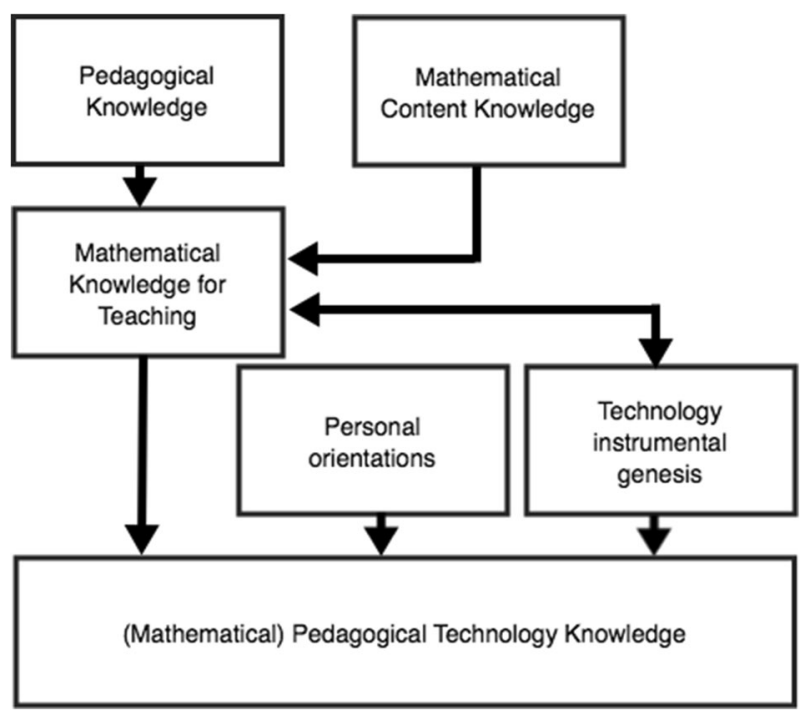

Fig. 1 Components of (mathematical) pedagogical technology knowledge (Thomas \& Hong, 2013; Thomas \& Palmer, 2014) 
- Mathematical content knowledge: A teacher's own knowledge of mathematics.

- Mathematical knowledge for teaching: The combination of a teacher's pedagogical knowledge alongside their mathematical content knowledge, as first defined by Ball et al. (2005).

- Personal orientations: The teachers' affective variables, that is their goals, attitudes, dispositions, beliefs, values, tastes, and preferences, as described by Schoenfeld (2011, p. 29), also incorporating their perceptions of the nature of mathematical knowledge and how it should be learned (with and without technology).

- Technology instrumental genesis: The process through which the teachers' mathematical knowledge shapes and is shaped by their interactions with the technology as they accomplish a particular mathematical task (Guin \& Trouche, 1999). Furthermore, for teachers, this genesis incorporates the development of the teachers' knowledge of pupils' (parallel) processes of instrumental genesis as a dual process, which impacts upon their mathematical knowledge/practice for teaching with technology, as indicated by the bidirectional arrow in Fig. 1 (Haspekian, 2014).

Our selection of this framework is informed by its mathematical foundations as, unlike the widely adopted "Technological Pedagogical Content Knowledge" or "TPACK" framework, MPTK acknowledges the following: the "epistemic value" of technological tools" (Artigue, 2002, p. 248) and the personal orientations of the teachers and the notion of a teachers' technology instrumental genesis. (These components are interrelated and complex and are more easily understood within the context of an example, which we present later in our findings).

\subsection{Cornerstone Maths: linear functions}

This paper focuses on the CM unit on linear functions. Digital technologies to support the representation and exploration of functions and graphs began to be developed in the 1980s; and, since then, a large body of research has concluded positive effects on pupils' learning, alongside identifying the challenges for teachers associated by their introduction to classrooms (Borba \& Confrey, 1996; Doerr \& Zangor, 2000; Lagrange, 2005). Doerr and Zangor, for example, highlighted the following: the need for teachers to evolve and adapt their teaching and how their roles, knowledge, and beliefs influenced their use of the technology (i.e., for visualization, transformation).

The CM linear function unit has its roots in the curriculum developed by Jim Kaput and colleagues as part of the NSF-funded "SimCalc" project (2004-2010) in the USA, which has been extensively evaluated and reported, concluding robust positive findings related to both improved student outcomes and the scalability of the approach in diverse classrooms in the USA (Hegedus \& Roschelle, 2013). (A more detailed description of the process of adapting the US approach and scaling in England is provided in Hoyles et al., 2013).

\subsection{Landmark activities}

Landmark activities provide the foci for the teacher professional development. We define landmark activities as those which provoke a rethinking of the mathematics or an extension of previously held ideas - the aha moments that show surprise - and provide evidence of pupils' developing appreciation of the underlying concept Fig. 2.

\footnotetext{
${ }^{2}$ Artigue defines the epistemic value of a tool thus, "capable of producing knowledge of the mathematical object under study, rather than those perceived and evaluated in terms of the productive potential or pragmatic value."
} 


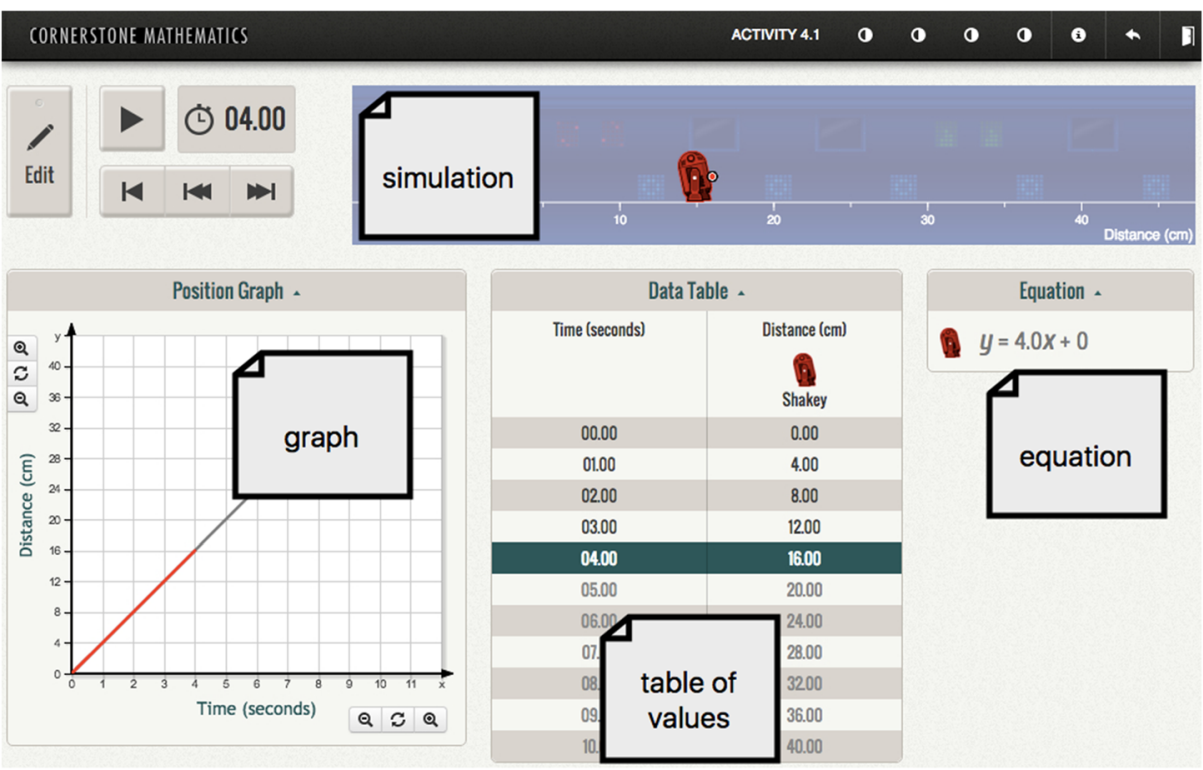

Fig. 2 Landmark activity: linear functions

For each CM unit, one landmark activity was selected as the focus for teachers' planning, teaching, and subsequent reflection, guided by the following criteria:

- It introduced a significant aspect of mathematical knowledge, i.e., the coordination of algebraic, graphical, and tabular representations and the meaning of " $\mathrm{m}$ " and " $\mathrm{c}$ " in the motion context using $\mathrm{y}=\mathrm{mx}+\mathrm{c}$ as a model of constant velocity motion (Kaput \& Roschelle, 1998; Romberg, Fennema, \& Carpenter, 1993).

- It included technological design features that offered new ways to engage with the mathematics, i.e., dynamic simulation and linking between representations where the simulation can be driven from the graph (through draggable "hotspots") or the function (by editing values), and representations can be shown or hidden as appropriate.

- It is selected from mid-way through the curriculum unit so that teachers and pupils should have some prior experience of the following: the mathematics (informal definitions of speed and familiarity with graphs and tables), the technology (playing the simulation and editing the graph), and context (advising on the mathematics to produce different simulations).

In this activity, the pupils begin by using the different representations to identify the character "Shakey's" speed. They then manipulate the activity by, for example, editing the graph using the draggable hotspots to explore how changing the gradient affects both the character's speed and the related mathematical representations, or by changing the parameters in the equation.

\subsection{Adapted "lesson study" approach}

The model for the PD was organized as an initial one-day PD session, followed by classroom trials and a half-day reflection session; to form a PD cycle, our adaptation of a feature of a lesson study approach given limited resources and whole departments was not involved 
(following Wake, Foster, \& Swan, 2013). This used the following cyclical rubric: identify a research focus (i.e., to develop pupils' appreciation of linear functions as a dynamic concept) $\rightarrow$ plan research lesson $\rightarrow$ teach research lesson $\rightarrow$ analyze research lesson $\rightarrow$ revise research lesson and $\rightarrow$ disseminate to colleagues. So, we chose the aforementioned CM activity and the teachers then planned (in pairs or trios) the following: the details of the lesson, how they would use the DMT, and their mediating role relating to DMT use. The lesson plans were created to a common template (see electronic supplementary materials) and shared electronically via the project's online community, which facilitated knowledge exchange, planning, and reflection practices.

\subsection{Research questions}

The project investigated three research questions (RQ). This paper addresses the latter two.

RQ1, What is the impact of teachers' engagement with cycles of professional development and associated teaching that embeds DMT on their MPTK relating to linear functions?

RQ2, What MPTK is desirable for teachers that allows them to integrate DMT in their teaching of linear functions?

RQ3, What are the design features of professional development activities for teachers of lower secondary mathematics that support them to use DMT in ways that become embedded in their practice and lead to effective learning?

\section{Methodology}

\subsection{Background to the Dynamic Technologies for Dynamic Mathematics study}

The research involved 42 London secondary schools between July 2015 and April 2017. All state-funded secondary schools in London were contacted and invited to participate; hence, the schools were self-selecting. Each school nominated or invited the teachers to participate, and we had no criteria for selection. In total, 209 teachers participated in the study. In this paper, we draw particularly from data provided by the 60 teachers who had both taken part in the linear functions PD cycle (the second in the series) and given their ethical consent to their data being used in the research. We use this data to give an exemplification of our methodology, which was replicated for the other two curriculum units. Furthermore, we conducted a focus group session with eight self-nominating CM champions, who were a self-selecting sample from the 27 teachers who had participated in all three PD cycles, and had indicated that they wanted to spread the innovation in their school.

\subsection{Methods}

Our overarching methodology aims to develop tools and conceptual models that "help us to understand and adjust both the context and the intervention so as to maximize learning" (Anderson \& Shattuck, 2012, p. 17). The study is complex involving multiple interactions between researchers and teachers, teachers and their pupils, and teachers and their colleagues. We do our best to communicate the complexities of our methods here. However, as the CM teaching curriculum has now arrived at a stable design, the PD toolkit is now the focus for the design research. Hence, we limit the description of our methodology to the main data sources 
analyzed to address the third research question. These sources are the teachers' lesson plans for the landmark activity, the enacted lessons (as evidenced by lesson observations) and key items from teacher surveys, and PD tasks.

\subsubsection{Data collection and analysis}

Across the study, we operationalized the MPTK framework by mapping our methodological tools as shown in Table 1.

Lesson plans for landmark activities The teachers' lesson plans for the landmark activities were a key methodological tool to provide insight into every component of their MPTK, as indicated in Table 1. As teachers had worked collaboratively to create them, the plans were analyzed as a representative data source at the research cohort level. Initially, a constant comparison process of analysis led to a set of eight hypothesized features of teachers' lesson plans that might indicate strong adherence to the original design principles of an intervention embedding DMT. The features were further refined during the process of data analysis, resulting in the set shown in Table 2, alongside an exemplification of each amalgamated from the research data.

For each lesson plan, the presence (or not) of each feature was noted as a simple indicator leading to the assignment of a score of between 0 and 8 . No account was taken of the frequency of each feature. However, when the plans were ordered by their total scores, it was possible to see a clear progression in their quality.

Lesson observations Our methodological decision to focus on a landmark activity meant that we only observed teachers when they were teaching that particular activity. In each PD cycle, we observed at least $10 \%$ of the teachers across a range of school and teacher contextual factors (school type, teaching experience, confidence with technology). Lesson observations were audio recorded, along with teacher interviews, prior to and immediately following the

Table 1 Components of MPTK and the methodological tools employed within the study

\begin{tabular}{|c|c|}
\hline Component of MPTK & Methodological tools used in the study \\
\hline \multirow[t]{3}{*}{ 1.Pedagogical knowledge } & a)Lesson plans for landmark activities \\
\hline & b)Lesson observations and interviews \\
\hline & c)Surveys: teachers' reflections on lesson outcomes \\
\hline \multirow[t]{3}{*}{ 2.Mathematical content knowledge } & a)Surveys: teachers' highest mathematical qualifications \\
\hline & b)Items in surveys and PD tasks \\
\hline & c)Lesson plans for landmark activities \\
\hline \multirow{4}{*}{ 3.Mathematical knowledge for teaching } & a)Items in surveys and PD tasks \\
\hline & b)Lesson plans for landmark activities \\
\hline & c)Lesson observations and interviews \\
\hline & d)Surveys: teachers' reflections on lesson outcomes \\
\hline \multirow[t]{4}{*}{ 4.Personal orientations } & a)Surveys: prior experiences with technology \\
\hline & b)Surveys: confidence levels to teach landmark activity \\
\hline & c)Lesson observations and interviews \\
\hline & d)Surveys: teachers' reflections on lesson outcomes \\
\hline \multirow[t]{4}{*}{ 5.Technology instrumental genesis } & a)PD tasks \\
\hline & b)Lesson plans for landmark activities \\
\hline & c)Lesson observations and interviews \\
\hline & d)Surveys: teachers' reflections on lesson outcomes \\
\hline
\end{tabular}


Table 2 Eight features of the linear functions' lesson plans and accompanying exemplifications from the data

Feature of linear functions' lesson plan

1. Explicit descriptions of teachers' actions/questions

2. Explicit descriptions of pupils' actions on DMT during the lesson

3. Appreciation of pupils' instrumental knowledge (i.e., prior skills with software, progression of skills in lesson)

4. Explicit reference to the meaning of functions (relating to other representations)

5. Explicit reference to acting on representations

6. Explicit use of mathematical vocabulary

7. Explicit use of technological/contextual vocabulary

8. Includes planned plenary phases that involved teacher use of software
Typical exemplification from teachers' plans

"Draw their attention to the screen - is there anything different from the previous day?"

"Come back together and project chosen students' screens onto the main screen and discuss answers"

"[Ask] How do we make Shakey go slowly? reminding them of the use of control buttons in controlling the time taken in the simulations"

"Students highlight hops on their graph and table which is the same as the gradient in their equation"

"let the students explore changing the steepness of the line and whether this means slower or faster"

"discuss where time, distance and speed is on the graph table and equation"

"Students hit the edit button and experiment with moving the graph (Ask how to make it steeper/ less steep etc.) what hotspots do you need to select"

"Play Shakey simulation. Ask students: How fast is Shakey going"

lesson. ${ }^{3}$ We positioned ourselves to observe the teacher's actions and did not intervene with pupils during the lessons. The contextual and descriptive features of the resulting phases of the lesson were noted, with particular emphasis on the teacher's actions and words in relation to the use of the dynamic technology during whole-class teaching and pupils' independent work. The lessons were transcribed and coded for evidence of the eight key features (Table 2).

Key items from the surveys and PD tasks Although a number of validated tools to assess teachers' mathematical knowledge for teaching and pedagogical content knowledge exist (i.e., the Learning Mathematics for Teaching project, 2011 and the TEDS-M study, Tatto, 2013), we were not aware of any that had been designed to both assess teacher knowledge within the context of DMT and addressed the mathematical topics relevant to our study. Hence, we drew on selected existing tools that served this particular purpose, including a number of items developed and validated in similar studies in the USA (Shechtman, Haertel, Roschelle, Knudsen, \& Singleton, 2010).

At the beginning of the PD cycle, teachers were individually surveyed to give a written definition of linear functions and to rate their confidence in their response (not at all confident, quite confident, confident, very confident). This task was immediately followed by small group discussions, prompted by the teachers' readings of their individual definitions in turn, during which they were encouraged to listen carefully for mathematical language, representations, notation, rigor, and completeness. We subsequently coded the written responses according to the richness of the mathematical references that they included, i.e., a relationship, a direct proportion, appearance of the graphical representation, gradient/intercept properties, and mapping.

Following their first introduction to the linear functions DMT, the teachers engaged in a PD task (see electronic supplementary materials) where they interacted with the DMT to establish how moving the draggable hotspots on the graphical representation affected the other

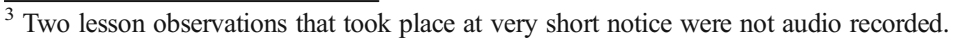


mathematical representations (simulation, table, and function). Following this, they were invited to explore other ways to edit the simulation. In both cases, teachers recorded both the steps they took and noted the impact of their actions using the DMT on each of the other representations.

\section{Key findings}

The prior use of DMT by the project teachers was low, despite the inspection criteria mentioned earlier. Fewer than one in five teachers reported that they were frequent users of DMT in their lower secondary teaching, and only one in three felt confident enough to do so $(n=111)$. With respect to pupils' use of DMT, fewer than one in eight teachers reported frequent use, although a greater proportion of teachers felt more confident in this setting. Just over a third of the teachers reported no prior use of a DMT by themselves or their pupils.

We report the key findings from the study that has impacted most on the design of the toolkit (RQ3): the nature of teachers' MPTK for the teaching of linear functions and the teachers' planning for and enactment of the landmark activity.

\subsection{Development of teachers' mathematical pedagogical technology knowledge for the teaching of linear functions}

Initially, many teachers seemed reluctant or lacked confidence to discuss linear functions in great depth, possibly as they were publicly exposing their mathematical content knowledge to a new and unfamiliar audience. We adopted pedagogical strategies to maintain the teachers' focus, which included expecting teachers to work individually on mathematics tasks prior to opening the discussion; encouraging the sharing of definitions, strategies, and solutions; and modeling an open classroom culture whereby teachers' views and opinions could be shared, while striving for mathematical rigor. Some teachers commented that they did not commonly discuss mathematical concepts (and related teaching) to this depth within their departments and that they had found these discussions very valuable.

Our data analysis concluded that the rigor of the teachers' initial definitions of linear functions varied greatly, with most teachers typically stating particular properties such as "a linear function is one that lies on a graph using $\mathrm{y}=\mathrm{mx}+\mathrm{c}$ to describe the gradient and intercept". Far fewer teachers framed their definitions within a broader definition of mathematical functions by considering, for example, the order of $x(18 \%, n=69)$ or the concept of a 1:1 mapping $(16 \%, n=69)$. The teachers' responses are in part explained by the way that the teaching of functions is commonly approached in English schools, which introduces linear and higher order functions separately and focuses mainly on graph plotting exercises and related problem solving (i.e., reading information from graphs).

The teachers' first introduction to the DMT proved to be a critical phase (see electronic supplementary materials for a description of the related task). Only half of the teachers paid attention to the hotspots in their descriptions of their interactions, despite us placing great emphasis on these during our introduction — and offering labels for the three hotspots: A, B, and C, as shown in Fig. 3. Teachers tended to use general language within pragmatic descriptions such as "we moved the green to 250 miles 5 hours and the blue to 250 miles at 6 hours" or "edit the blue car to win," with no detail about which hotspot they were dragging and how. Alternatively, a description such as "B changes the length of the line (restricting the domain)" and dragging A "extends position and changes 

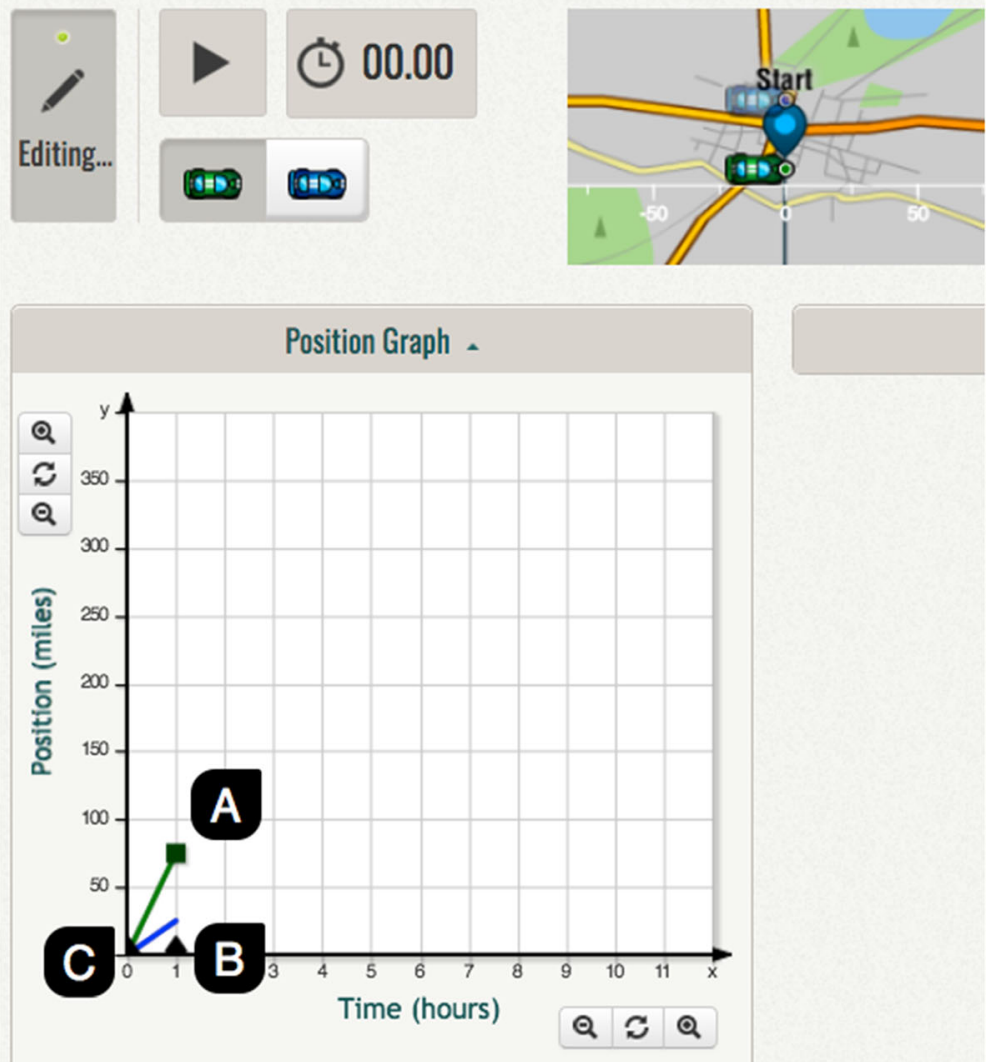

Fig. 3 Opening screen for the linear functions PD task, showing the three "hotspots", labeled A, B, and C. (The complete PD task is described in the electronic supplementary materials.)

gradient" implied that the teacher was beginning to develop a more epistemic understanding of the DMT.

We conjecture that, if teachers had not articulated both their own dragging actions using the technology and how these actions impacted mathematically on the context, they might struggle to support their pupils to do the same. Furthermore, the absence of clear vocabulary to describe such actions (and their outcomes) might also hinder subsequent classroom discussion. The teachers' initial engagement with the DMT prompted much interest and, although many teachers struggled initially to makes sense of the dynamic aspects, in particular the mathematical nuances of dragging the hotspots, nearly all reported that they saw some value in the potential afforded by the technology. The motion context, supported by the animation, had enabled teachers to make the important connections between the value of the coefficient of $x$, the gradient of the line segment on the graph, and the multiplicative and additive relationships inherent within the table in ways that suggested they had rethought their prior understanding.

\subsection{Lesson planning for the linear functions landmark activity}

This analysis of the teachers' lesson plans provided insight into their espoused MPKT (addressing RQ2) as they prepared to teach the lessons. We were keen to see if and how their 
engagement with the PD tasks described above had impacted on the teachers' thinking as they devised their lesson plans. Forty-two lesson plans that had been produced in pairs and trios by $65^{4}$ teachers were analyzed and the frequencies of each feature are shown (see Table 3 ).

The analysis of the lesson plans revealed that just over one third of plans included five or more of the desirable features, which in most cases excluded those which directly involved the technology (i.e., features 2, 3, 5, 7, and 8). Approximately one half of the plans were explicit about the way in which the pupils would use the DMT (feature 2). A quarter of the plans indicated an intention to use the DMT during a whole-class plenary (i.e., feature 8). In many cases this was to play the original animation to the class. Very few plans went further to include explicit discussion or demonstration of the editable "hot spots" on the graph that controlled the animation in relation to the mathematical purpose that each served (i.e., varying the speed, start position, and overall journey time). This was surprising to us since the initial PD session had allowed the teachers almost an hour to explore, discuss, and make sense of this fundamental aspect of the DMT. It is as though their personal struggle had been forgotten as soon as they had made sense of the hot spots such that they did not imagine that their pupils would need substantial time and support to reach the same level of fluency. The quality of the planning was variable with the distribution of quality scores for lesson plans being $(n=42, \overline{\mathrm{x}}=4.2, \mathrm{SD}=$ 2.1).

\subsection{Lesson enactment for the linear functions landmark activity}

Fourteen lesson enactments taught by fifteen of the project teachers were observed (one lesson was team-taught), providing a rich data set to address RQ2, which sought to identify "desirable MPTK" for teaching with dynamic technology. All teachers had access to a data projector and an interactive whiteboard. The observed classes spanned the age range (11-14 years), and all pupils engaged directly with the landmark activity during the lessons. However, it is a notable finding that seven of the teachers did not interact directly with the DMT while convening whole-class plenaries during the lesson, although one of these teachers did select a pupil to do so. Instead, three of these teachers displayed images of the software ("screen grabs") within static presentation slides, while the remainder only displayed the landmark activity in the DMT. Post-lesson interviews with these teachers provided a strong indication that they lacked the confidence and competence to use the DMT "live" in the classroom, even though several had planned such actions in their lesson plans. This suggests the need for more specific exemplification of such use, by including short videos of other teachers to prompt professional discussion.

\subsection{Making sense of MPTK through observed practice}

We present an analysis of a 3.5 min phase in Darren's class as an insight into the interrelated and complex nature of his MPTK as seen through his practice. The students had been instructed to work for about 10 min (in pairs) to play the simulation, decide how fast Shakey was going, and record how they knew. See the electronic supplementary materials for the full transcript.

\footnotetext{
${ }^{4}$ Five teachers took part in the linear functions lesson planning PD activity who had not participated in the associated teacher surveys.
} 
Table 3 Linear functions: summary of lesson plan analysis (42 lesson plans)

\begin{tabular}{lll}
\hline Feature of lesson plan & Frequency & $\%$ \\
\hline 1. Explicit descriptions of teachers' actions/questions & 29 & 69 \\
2. Explicit descriptions of pupils' actions on DMT during the lesson & 19 & 45 \\
3. Appreciation of pupils' instrumental knowledge & 16 & 38 \\
4. Explicit reference to meaning of functions (relating to other representations) & 24 & 57 \\
5. Explicit reference to acting on representations to change speed & 11 & 26 \\
6. Explicit use of mathematical vocabulary & 26 & 62 \\
7. Explicit use of technological/contextual vocabulary & 13 & 31 \\
8. Planned plenary phases that involved teacher use of software & 10 & 24 \\
\hline
\end{tabular}

Darren's MPTK was evidenced through his choice of vocabulary, gestures, and actions involving the DMT. He began by stating the correct answer ( $4 \mathrm{~cm}$ per second), and in the subsequent phase of whole-class teaching, he listened to (and helped students to articulate) their different approaches to find Shakey's speed. He did not rush the students nor did he gloss over any comments, suggesting both sound pedagogical knowledge and highly positive relationships with his students. His mathematical knowledge for teaching, which had been enhanced by his own instrumental genesis with the DMT, enabled him to make sense of the students' approaches and model the use of the DMT to make different approaches more explicit to the class as a whole. He noticed the subtlety of one student's contribution by recognizing that she may have identified more than one way to use the table to establish the speed for this particular example (i.e., a function of the type $y=\mathrm{a} x$ ). Darren used this phase efficiently as a means to highlight the different representations (and how they might relate to the Shakey's speed) and to model how students might draw information from these representations. In doing so, he offered the students dynamic strategies to exploit the power of the DMT in the task that followed, which involved changing the character's speed and noticing how this impacted on the different representations.

\section{Development of web-based PD toolkit}

We outlined earlier the need to support in-school scaling, and here we set out the components of the CM PD toolkit. Overview, Getting started, Curriculum Units and PD Resources, Embedding (CM in departmental practices), Evidence base, and Project community, these components are described in the electronic supplementary materials and the toolkit can be accessed at www.ucl.ac.uk/cornerstone-maths.

Elements such as the Overview, Getting started, Evidence base, and Embedding respond to the identified need to communicate key aspects of the project in order to engage the school leadership and departmental colleagues initially or, once school buy-in had been achieved, to embed CM into schemes of work. These key aspects of scaling and sustainability, previously identified by Coburn and others (Coburn, 2003; Earl et al., 2003) were further validated by our $\mathrm{CM}$ champions, who proposed pragmatic content for the toolkit.

We focus here on the findings that address RQ3 concerning the element of the toolkit that has most potential to impact on teachers' MPTK, the Curriculum Units and PD Resources.

\footnotetext{
${ }^{5}$ This component is replicated for the three CM curriculum topics.
} 
During our focus group meeting with the CM champions, we were surprised that, even though the teachers had experienced 8 hours of PD activity related to the curriculum unit, none mentioned any PD activities that had addressed the fundamental mathematical ideas within the unit. We hypothesize that the nature of such PD activities is outside the norms of most withinschool professional activity. This is supported by the CM champions' descriptions of the PD activities they had already initiated in their schools, which tended to be demonstrating the CM software to colleagues and sharing the outcomes of CM lessons with them. Furthermore, as our data reviewed that the teachers' introduction to the linear functions DMT was a critical phase in the development of their MPTK, it was not sufficient for them to only watch a PD leader or colleague interacting with the DMT. It was essential that they had the tangible experience of moving the draggable points and appreciating the underlying constraints. These findings impacted on the subsequent design of the PD toolkit through the inclusion of:

- A dynamic screen capture video introduction to the linear functions DMT with supporting narration, drawing attention to the mathematical constraints of the three hotspots, and the underlying rationale for this design.

- Presentation slides for the CM champions to use and adapt that support:

- A PD discussion about linear functions

- $\quad$ Teachers' first hands-on experiences with the DMT

Feedback from the CM champions led to a redesign of the lesson planning task to align with a school-based model that could be communicated through the PD toolkit. Although the lesson study PD approach had been new to the vast majority of project teachers, two schools adopted the approach wholeheartedly and reported how teachers had been enabled to work and learn collaboratively (see for example, Clark-Wilson, 2017). However, although other teachers became more interested, the majority had neither the institutional support nor the necessary time with colleagues to formalize this approach.

Moreover, the project had generated a set of video clips of teachers' classroom implementations of the landmark activity (recorded by both the researchers and a few teachers), alongside samples of pupils' written work that had been selected by teachers for discussion during the face-to-face post-teaching PD sessions. While the value of this data during the project was obvious, we worked with the PD champions to select key resources that could be included in the toolkit to support teachers' planning for the landmark activity, while also promoting the value of using classroom-generated data to support the Analyze and Revise processes within the lesson study cycle.

To summarize, the specific design features relating to the lesson planning task that ware integrated within the toolkit are:

- A PD resource to outline the "lesson study approach" focused on the linear functions landmark activity

- The lesson planning template and links to the CM project online community where the teachers had shared their plans

- Dynamic screen capture narrated videos of linear functions landmark activity, outlining the pupil task and highlighting the important mathematical ideas

- Video clips of teachers' mediation of the DMT during the landmark activity

- Examples of typical pupils' written work from the landmark activity 


\section{Conclusions and future directions for research}

The DMDT project has identified key components of teachers' MPTK for teaching lower secondary mathematics topics with dynamic technologies as evidenced through their lesson plans and classroom enaction. The complexities of such practice are highlighted through the analysis of Darren's lesson transcript, which aligns tightly with Thomas and Palmer's generic description of teachers with high MPTK:

[They] relate the technology to linking multiple representations of constructs, understanding of ideas, generalization and moving from step-by-step processes to an overview. They have advanced to the point where they are competent in instrumentation of the technology and are able to focus on other important aspects, such as the linking of graphical, tabular, algebraic, ordered pair and other representations. .... They feel free to loosen control and encourage pupils to engage with conceptual ideas of mathematics through individual and group exploration, investigation of mathematical ideas, and the use of methods, such as prediction and testing. (Thomas \& Palmer, 2014, pp. 85-86)

The important recommendation by Thomas and Palmer (2014) that it appears beneficial for teachers to "be part of a group that shares and reflects on their knowledge and instrumentation, practical classroom activities and ideas - especially at the initial stages of learning" (2014, p. 85) did not go as far to suggest the PD models or structures through which this might be achieved. In our work, we have sought to address this gap from the context of the English school system with its particular institutional constraints and national issues, such as the current mathematics teacher shortage, which acts as a barrier to schools sustaining innovations and practices.

The PD toolkit has the potential to overcome two of the teacher-reported barriers to increased use of DMT: "increased knowledge of suitable DMTs" and "better access to suitable resources"; and, although the allocation of personal and departmental time is beyond our control, early feedback from CM champions who have piloted the toolkit during its design phase suggests that the framework that it offers provides an incentive for schools to allocate time for teachers to engage with it.

Our study has advanced knowledge of the nature of professional development activities that support teachers to implement DMT in their classrooms, which need to blend face-to-face sessions that involve first-hand experiences with the DMT alongside PD tasks that deepen teachers' understandings of the mathematics involved and promote lesson planning for common activities. The PD toolkit resources extended beyond resources for PD sessions for other teachers of key stage three to include resources to support the wider communication of research findings that underpinned the use of DMT, and case studies of successful departmental implementations of DMT in various schools.

Furthermore, we concur with the earlier conclusion made by Roschelle, Tatar, Shechtman and Knudsen that "being more specific and less ambitious in first implementations but relaxing these constraints as teachers gain experience makes sense" when designing PD models to scale the use of DMT (2008, p. 167). We extend this idea further by focusing the PD activity on the planning, teaching, and reflection of landmark activities.

Our next step is to evaluate the impact of the PD toolkit on teachers' MPTK in the situated setting of the mathematics department. We conjecture that the PD toolkit and its underlying theoretical construct of the landmark activity might offer a scalable model to evaluate the implementation fidelity of $\mathrm{CM}$ over time when the researcher support has long-faded. A 
measure of success would be the increased proportion of teachers in the department who teach lower secondary classes that have taken up the CM curriculum units in their teaching and continued to teach the units to a high level of fidelity over several years.

Acknowledgements The development of Cornerstone Maths (2010-2013) was funded initially by the Li Ka Shing Foundation, an intensive collaboration between teams at the UCL Knowledge Lab, UCL Institute of Education, UK and at the Center for Technology in Learning, SRI International, USA.

The research reported is part of the Dynamic Technologies for Dynamic Mathematics Project (DMDT), funded by the Nuffield Foundation (award reference 9190). The views expressed are those of the authors and not necessarily those of the foundation.

Open Access This article is distributed under the terms of the Creative Commons Attribution 4.0 International License (http://creativecommons.org/licenses/by/4.0/), which permits unrestricted use, distribution, and reproduction in any medium, provided you give appropriate credit to the original author(s) and the source, provide a link to the Creative Commons license, and indicate if changes were made.

\section{References}

Aldon, G., Artigue, M., Barzel, B., Clark-Wilson, A., Drijvers, P., Lokar, M., ... Weigand, H.-G. (2012). EdUmatics. http://www.edumatics.mathematik.uni-wuerzburg.de/en/

Anderson, T., \& Shattuck, J. (2012). Design-based research: A decade of progress in education research? Educational Researcher, 41(1), 16-25. https://doi.org/10.3102/0013189X11428813

Artigue, M. (2002). Learning mathematics in a CAS environment: The genesis of a reflection about instrumentation and the dialectics between technical and conceptual work. International Journal of Computers for Mathematical Learning, 7(3), 245-274. https://doi.org/10.1023/A:1022103903080

Ball, D. L., Hill, H. C., \& Bass, H. (2005). Knowing mathematics for teaching: Who knows mathematics well enough to teach third grade, and how can we decide? American Educator (Fall 2005), 14-46.

Borba, M. C., \& Confrey, J. (1996). A student's construction of transformations of functions in a multiple representational environment. Educational Studies in Mathematics, 31(3), 319-337.

Borneleit, P., Danckwerts, R., Henn, H.-W., \& Weigand, H.-G. (2001). Expertise in the teaching of mathematics in the grammar school. In H.-E. Tenorth (Eds.), Kerncurriculum Oberstufe. (pp. 26-53). Weinheim: Beltz.

Bowland Maths. (2007). The Bowland Professional Development Modules. http://www.bowlandmaths.org. $\mathrm{uk} / \mathrm{pd} / \mathrm{index} \cdot \mathrm{html}$

Clark-Wilson, A. (2017). Transforming mathematics teaching with digital technologies - a community of practice perspective. In A. Marcus-Quinn \& T. Hourigan (Eds.), Handbook on digital learning for K-12 schools (pp. 45-58). Dordrecht: Springer.

Clark-Wilson, A., \& Hoyles, C. (2017). Developing teachers' mathematical knowledge for teaching through engagement with key mathematical concepts using dynamic digital technology. London: UCL Institute of Education.

Clark-Wilson, A., Hoyles, C., Noss, R., Vahey, P., \& Roschelle, J. (2015). Scaling a technology-based innovation: Windows on the evolution of mathematics teachers' practices. ZDM Mathematics Education, 47(1), 79-92. https://doi.org/10.1007/s11858-014-0635-6

Coburn, C. (2003). Rethinking scale: Moving beyond numbers to deep and lasting change. Educational Researcher, 32(6), 3-12.

Cobb, P., Jackson, K., Smith, T., \& Henrick, E. (2017). Supporting improvements in the quality of mathematics teaching on a large scale. In S. Doff \& R. Komoss (Eds.), Making change happen (pp. 203-221). Wiesbaden: Springer Fachmedien Wiesbaden.

Department of Education. (2013). National Curriculum in England. In Mathematics programmes of study: Key stage 3. London: Department of Education.

Des Clayes, Z. (2017). Teacher retention: Are England's teachers leaving? Slough: NFER. Retrieved from https://www.nfer.ac.uk/publications/FFEE05

Doerr, H., \& Zangor, R. (2000). Creating meaning for and with the graphing calculator. Educational Studies in Mathematics, 41, 143-163.

Earl, L. M., Warson, N., \& Katz, S. (2003). Large-scale education reform: Life cycles and implications for sustainability. Reading: CfBT. 
Guin, D., \& Trouche, L. (1999). The complex process of converting tools into mathematical instruments: The case of calculators. International Journal of Computers for Mathematical Learning, 3(3), 195-227.

Haspekian, M. (2014). Teachers' instrumental geneses when integrating spreadsheet software. In A. ClarkWilson, O. Robutti, \& N. Sinclair (Eds.), The mathematics teacher in the digital era: An international perspective on technology focused professional development (pp. 241-276). Dordrecht: Springer.

Hegedus, \& Roschelle, J. (2013). The SimCalc vision and contributions. Dordrecht: Springer.

Hoyles, C., Noss, R., Vahey, P., \& Roschelle, J. (2013). Cornerstone Mathematics: Designing digital technology for teacher adaptation and scaling. ZDM Mathematics Education, 45(7), 1057-1070. https://doi.org/10.1007 /s11858-013-0540-4

Kaput, J., \& Roschelle, J. (1998). The mathematics of change and variation from a millenial perspective: Now content, new context. In C. Hoyles, C. Morgan, \& G. Woodhouse (Eds.), Rethinking the mathematics curriculum (pp. 155-170). London: Springer-Verlag.

Lagrange, J.-B. (2005). Curriculum, classroom practices, and tool design in the learning of functions through technology-aided experimental approaches. International Journal of Computers for Mathematical Learning, 10(2), 143-189.

Learning Mathematics for Teaching Project. (2011). Measuring the mathematical quality of instruction. Journal of Mathematics Teacher Education, 14(1), 25-47. https://doi.org/10.1007/s10857-010-9140-1

Roesken-Winter, B., Hoyles, C., \& Blömeke, S. (Eds.). (2015). Evidence-based CPD: Scaling up sustainable interventions. ZDM Mathematics Education, 47(1), 1-12.

Roesken-Winter, B., Schüler, S., Stahnke, R., \& Blomeke, S. (2015). Effective CPD on a large scale: Examining the development of multipliers. ZDM Mathematics Education, 47(1), 13-25. https://doi.org/10.1007/s11858014-0644-5

Romberg, T., Fennema, E., \& Carpenter, T. (Eds.). (1993). Integrating research on the graphical representation of functions. Hillsdale, NJ: Erlbaum.

Roschelle, J., Tatar, D., Shechtman, N., \& Knudsen, J. (2008). The role of scaling up research in designing for and evaluating robustness. Educational Studies in Mathematics, 68(2), 149-170. https://doi.org/10.1007 /s10649-008-9119-3

Schoenfeld, A. (2011). How we think. A theory of goal-oriented decision making and its educational applications. New York: Routledge.

Shechtman, N., Haertel, G., Roschelle, J., Knudsen, J., \& Singleton, C. (2010). Scaling up SimCalc project. Design and development of the student and teacher mathematical assessments (technical report 05). Menlo, CA: SRI International.

Shulman, L. (1987). Knowledge and teaching: Foundations of the new reform. Harvard Educational Review, $56(1), 1-22$.

Sturman, L., \& Cooper, L. (2012). Evaluation of Cornerstone Mathematics pilot in England: Unit 1, linear functions. Berkshire: National Foundation for Educational Research.

Tatto, M. T. (Ed.). (2013). The teacher education and development study in mathematics: Technical report. Netherlands: International Association for the Evaluation of Educational Achievement.

Thomas, M. O. J., \& Hong, Y. Y. (2013). Teacher integration of technology into mathematics learning. International Journal for Technology in Mathematics Education, 20(2), 69-84.

Thomas, M. O. J., \& Palmer, J. (2014). Teaching with digital technology: Obstacles and opportunities. In A. Clark-Wilson, O. Robutti, \& N. Sinclair (Eds.), The mathematics teacher in the digital era: An international perspective on technology focused professional development (pp. 71-89). Dordrecht: Springer.

Wake, G., Foster, C., \& Swan, M. (2013). A theoretical lens on lesson study: Professional learning across boundaries. In A. Lindmeier \& A. Heinze (Eds.), Proceedings of the 37th conference of the International Group for the Psychology of Mathematics Education (Vol. 4, pp. 369-376). Kiel: PME.

Zehetmeier, S., \& Krainer, K. (2011). Ways of promoting the sustainability of mathematics teachers' professional development. ZDM Mathematics Education, 43(6-7), 875-887. https://doi.org/10.1007/s11858-011-0358-x 